\title{
ENERGY-MASS DISTRIBUTIONS IN INDUCED FISSION
}

\author{
F. PLASIL, D. S. BURNETT and S. G. THOMPSON \\ Lawrence Radiation Laboratory, Berkeley, California
}

Introduction. - Recently Nix and Swiatecki have been able to expand the liquid drop theory of nuclear fission to consider dynamics as well as statics of charged liquid drops [1]. By solving the equations of motion for a fissioning system, and combining the results with the assumption of statistical equilibrium at the saddle, they have been able to calculate a bivariate distribution for the fission fragments. The two variables of this distribution are the mass of one fragment and the total kinetic energy released in the fission event. The measurement of such distributions and their comparison with theory is the subject of this paper. Two important features of these distributions are : (a) they are derived from basic principles, and use standard nuclear constants, thus leaving no room for adjustable parameters; (b) the widths of the distributions are functions of the nuclear temperature at the saddle. In the theoretical calculations the nucleus was treated in the "spheroid approximation », which pictures the fissioning system as two spheroids that may be overlapped, tangent to each other, or separated. This approximation results in restricting the validity of this model to relatively light elements (lighter than about radium). For this reason we concern ourselves with bombardments of elements ranging from erbium to bismuth.

Experimental. - The energies of both fission fragments from every event considered were measured with solid state detectors and recorded in a correlated manner. The energy data have been transformed to give mass-total kinetic energy density-of-events distributions. Spontaneous fission of $\mathrm{Cf}^{252}$ has been used to calibrate the detectors and the electronic system. Details of experimental procedure and of data processing are given in ref. [2] and [3]. Table 1 gives the reactions studied. Heary ions were used in some cases to enhance fissionability. Due to resulting high excitations, the problem of determining the nuclear temperature $\theta$ at fission was complicated by the possibility of fission following neutron evaporation. The method used in obtaining $\theta$ values of table 1 is discussed in ref. [3].

Results and Discussion. - The measured distributions may be directly compared with the theoretical distributions after correcting for the effects of neutron evaporation. The method of correction is given in ref. [2]. Comparisons of the values of the average total kinetic energy released $\left\langle E_{\mathrm{T}}\right\rangle$, and of the variances of overall mass, $\mu_{2}\left(A_{1}\right)$, and total kinetic energy, $\mu_{2}\left(E_{T}\right)$, distributions are given in table 1 . (Variance is a measure of the width of a distribution.) The agreement is seen to be remarkably good. The estimated errors in experimental quantities are up to \pm 0.5 in $\theta, \pm 6 \mathrm{MeV}$ in $\left\langle E_{\mathrm{T}}\right\rangle$, $\pm 10(\mathrm{MeV})^{2}$ in $\mu_{2}\left(E_{\mathrm{T}}\right)$ and $\pm 15(\mathrm{amu})^{2}$ in $\mu_{2}\left(A_{1}\right)$. 
TABLE 1

\begin{tabular}{|c|c|c|c|c|c|c|c|c|c|c|c|c|c|}
\hline System & & Er170 & $+0^{16}$ & & Yb174 & $+\mathrm{C}^{12}$ & & & $82+$ & & & $\mathrm{Au}^{197}+\mathrm{He}^{4}$ & $\mathrm{Bi}^{200}+\mathrm{He}^{t}$ \\
\hline Bombarding Energy & 165 & 151 & 136 & 120 & 125 & 109 & 165 & 144 & 127 & 115 & 102 & 70 & 65 \\
\hline Nuclear Temperature & 2.06 & 1.91 & 1.73 & 1.49 & 1.70 & 1.53 & 2.07 & 1.87 & 1.70 & 1.55 & 1.37 & 1.28 & 1.13 \\
\hline $\begin{array}{l}\left(E_{\mathrm{T}}\right) \text { Experiment } \\
\left(E_{\mathrm{T}}\right) \text { Theory }\end{array}$ & $\begin{array}{l}127 \\
131\end{array}$ & $\begin{array}{l}128 \\
131\end{array}$ & $\begin{array}{l}124 \\
131\end{array}$ & $\begin{array}{l}124 \\
131\end{array}$ & $\begin{array}{l}129 \\
131\end{array}$ & $\begin{array}{l}127 \\
131\end{array}$ & $\begin{array}{l}147 \\
143\end{array}$ & $\begin{array}{l}146 \\
143\end{array}$ & $\begin{array}{l}146 \\
143\end{array}$ & $\begin{array}{l}144 \\
143\end{array}$ & $\begin{array}{l}144 \\
143\end{array}$ & $\begin{array}{l}142 \\
142\end{array}$ & $\begin{array}{l}150 \\
150\end{array}$ \\
\hline $\begin{array}{l}\mu_{2}\left(E_{\mathrm{T}}\right) \text { Experiment } \\
\mu_{2}\left(E_{\mathrm{T}}\right) \text { Theory }\end{array}$ & $\begin{array}{l}106 \\
116\end{array}$ & $\begin{array}{r}96 \\
108\end{array}$ & $\begin{array}{l}97 \\
97\end{array}$ & $\begin{array}{l}89 \\
82\end{array}$ & $\begin{array}{r}104 \\
95\end{array}$ & $\begin{array}{l}94 \\
85\end{array}$ & $\begin{array}{l}135 \\
123\end{array}$ & $\begin{array}{l}116 \\
111\end{array}$ & $\begin{array}{l}108 \\
101\end{array}$ & $\begin{array}{l}96 \\
92\end{array}$ & $\begin{array}{l}85 \\
81\end{array}$ & $\begin{array}{l}69 \\
74\end{array}$ & $\begin{array}{l}74 \\
70\end{array}$ \\
\hline $\begin{array}{l}\mu_{2}\left(A_{1}\right) \text { Experiment } \\
\mu_{2}\left(A_{1}\right) \text { Theory }\end{array}$ & $\begin{array}{l}235 \\
249\end{array}$ & $\begin{array}{l}215 \\
235\end{array}$ & $\begin{array}{l}211 \\
213\end{array}$ & $\begin{array}{l}199 \\
186\end{array}$ & $\begin{array}{l}211 \\
211\end{array}$ & $\begin{array}{l}185 \\
190\end{array}$ & $\begin{array}{l}243 \\
205\end{array}$ & $\begin{array}{l}229 \\
186\end{array}$ & $\begin{array}{l}203 \\
170\end{array}$ & $\begin{array}{l}185 \\
155\end{array}$ & $\begin{array}{l}156 \\
137\end{array}$ & $\begin{array}{l}137 \\
147\end{array}$ & $\begin{array}{l}131 \\
126\end{array}$ \\
\hline
\end{tabular}

As can be noted from the table, the theoretical and experimental results are found to agree not only in terms of absolute magnitude, but also in their temperature dependence. More detailed comparisons and references are to be found in ref. [1], [2] and [3] of this paper. Certain disagreements do exist in the fine features of the distributions, especially in the heavy ion bombardments [3]. They may be in part due to angular momentum effects. It is hoped that further experimental investigation (with greater numbers of events and a larger range in $\theta$ values) coupled with/a refinement of the theory (a hyperbolic neck inserted between the two spheroids has yielded excellent results in preliminary static calculations) will make it possible to explain the discrepancies and define the limits of the applicability of the liquid drop model to the fission process, at least for relatively light elements.

\section{REFERENCES}

[1] J. R. NIx, Univ. California Radiation Lab. Rep. UCRL-11338, March 1964.

[2] D. S. Burnetr, Univ. California Radiation Lab. Rep. UCRL-11006, October 1963.

[3] F. Plasil, Univ. California Radiation Lab. Rep. UCRL-11193, December 1963. 